Michael Cebulla - Wahrheit und Authentizität

Zur Entwicklung der Literaturtheorie Paul de Mans 


\section{Michael Cebulla}

\section{Wahrheit und \\ Authentizität}

\section{Zur Entwicklung der Literaturtheorie Paul de Mans}


Die Deutsche Bibliothek - CIP-Einheitsaufnahme

\section{Cebulla, Michael:}

Wahrheit und Authentizität : zur Entwicklung der

Literaturtheorie Paul de Mans / Michael Cebulla. - Stuttgart :

$M$ und P, Verl. für Wiss. und Forschung, 1992

(M-\&-P-Schriftenreihe für Wissenschaft und Forschung)

Zugl.: Berlin, Freie Univ., Diss., 1992

ISBN 978-3-476-45010-4

D 188

ISBN 978-3-476-45010-4

ISBN 978-3-476-04168-5 (eBook)

DOI 10.1007/978-3-476-04168-5

Dieses Werk ist einschließlich aller seiner Teile geschützt. Jede Verwertung außerhalb der engen Grenzen des Urheberrechtsgesetzes ist ohne Zustimmung des Verlages unzulässig und strafbar., Das gilt insbesondere für Vervielfältigungen, Übersetzungen, Mikroverfilmungen und Einspeicherung in elektronischen Systemen.

M \& P Verlag für Wissenschaft und Forschung ein Verlag der J. B.Metzlerschen Verlagsbuchhandlung und Carl Emst Poeschel Verlag GmbH in Stuttgart

(c) 1992 Springer-Verlag GmbH Deutschland Ursprünglich erschienen bei J.B. Metzlersche Verlagsbuchhandlung und Carl Ernst Poeschel Verlag GmbH in Stuttgart 1992 


\section{Inhalt}

\section{Erstes Kapitel:}

Wissen und Zeitlichkeit 1

I.Subjektivität und Erkenntnis $\quad 11$

1.Subjektivität und Tradition $\quad 11$

2.Epoché 14

3.Zeitlichkeit und Transzendenz 16

4.Verendlichung der Phänomenologie 18

5.Intentionalität und Begierde 21

6.Wahrnehmung und Zweideutigkeit 24

7.Das Scheitern und die Form 27

II.Das Werk 31

1.Setzung und Zeitlichkeit 31

2.Werk und Arbeit 39

3.Die Unwirklichkeit des Kunstwerks 49

\section{Zweites Kapitel:}

Stilistik und Geschichte $\quad 54$

L.Paul de Mans Kritik des Formalismus $\quad 56$

1.T.S.Eliot und Cleanth Brooks 56

2.William Empson $\quad 59$

3.Paul de Man 61

II.Textuelle Begierde $\quad 65$

1.Sprache als Beschwörung $\quad 67$

2.Das poetische Bild 70

3.Symbolistisches Bild und Emblem $\quad 76$ 


\section{Drittes Kapitel:}

Literatur und Kritik $\quad 84$

L.Kritik $\quad 86$

1.Kritik und Krise $\quad 86$

1.Rhetorik der Krise 86

2.Standpunkt des Beobachters $\quad 88$

3.Geschichtlichkeit und Krise $\quad 90$

4.Wissen und Geschichtlichkeit 93

5.Authentizität 97

2.Zirkularität und Zeitlichkeit $\quad 100$

1.Unhintergehbarkeit der Zirkularität 101

2.Zeitlichkeit 104

3.Zirkularität 107

4.Einsicht 111

II.Temporalität und Textualität $\quad 116$

5.Allegorie bei Benjamin $\quad 117$

1.Allegorie und Bedeutung $\quad 117$

2.Allegorie und Authentizität $\quad 119$

3.Allegorische Interpretation 121

6.Zeitlichkeit und Allegorie 123

7.Allegorie und Zeitlichkeit $\quad 128$

Viertes Kapitel:

Allegorien des Lesens 132

1.Negative Totalität 132

2.Rhetorik 137

3.Mißglückte Selbstreferenz $\quad 145$

1.Jakobson und Genette $\quad 146$

2.De Man und Genette 149

4.Allegorie und Begriff $\quad 154$

5.Unlesbarkeit 158

6.Dekonstruktion 161

1.Dekonstruktion und Kritk $\quad 162$

2.Derridas Strukturalismus-Kritik $\quad 164$ 
7.Unentscheidbarkeit

8.Setzung und Erkenntnis

1.Austin und Derrida

2.Authentizität und Wahrheit

\section{Fünftes Kapitel:}

Begegnungen mit Theorie

1.Lesen als imaginäre Begegnung

2.Rezeptionsästhetik

1.Wolfgang Iser

2.Stanley E. Fish

192

3.De Mans Metakritik

194

3.Intertextualität

200

4.Lese-Erzählungen

204

5.Theorie und Geschichtlichkeit 